\title{
Distinctive biochemical changes in pulmonary tuberculosis and pneumonia
}

\author{
Füsun Șahin, Pınar Yıldız
}

Department of Pulmonology, Yedikule Chest Diseases and Thoracic Surgery Training and Research Hospital, Istanbul, Turkey

Submitted: 27 March 2012

Accepted: 19 June 2012

Arch Med Sci 2013; 9, 4: 656-661

DOI: $10.5114 /$ aoms.2013.34403

Copyright @ 2013 Termedia \& Banach

\section{Abstract}

Introduction: We aimed to investigate the relationship between radiological extent and serum biochemical changes and body mass index (BMI) in patients with pulmonary tuberculosis (PTB) and pneumonia and to determine the usefulness of C-reactive protein (CRP) in clinical discriminative diagnosis.

Material and methods: One hundred fifteen patients with tuberculosis (group 1), 70 patients with pneumonia (group 2) and 30 healthy controls (group 3) were included in this case-control study.

Results: Total cholesterol (TC, $p<0.001$ in group 1; $p=0.011$ in group 2), highdensity lipoprotein (HDL, $p<0.001)$, albumin (ALB, $p<0.001)$ and BMI $(p<0.001)$ values were significantly lower group 1 and group 2 than group 3. Erythrocyte sedimentation rate (ESR), leucocyte (LEU) and CRP were higher in group 2 than group 1 and group $3(p<0.001)$. As important point; triglyceride (TG) and BMI were significantly lower in group 1 than group $2(p<0.001)$. In group $1 ; B M I, H D L$, TG, total protein (TP) and albumin were found to decrease, while CRP and ESR increased as the radiological stage increased $(p<0.05)$. But no significant difference was found in levels of TC and LDL $(p>0.05)$. In group 2; BMI, TC, HDL, LDL, TP and ALB were observed to decrease, while LEU, CRP and ESR increased as the radiological stage increased $(p<0.05)$. But no significant difference was found in levels of TG $(p>0.05)$. The best serum CRP cut-off value in differential diagnosis of tuberculosis and pneumonia was defined as 9.4.

Conclusions: The acute phase response occurring in tuberculosis and pneumonia determines the severity of the disease, leads to a decrease of serum levels of lipoproteins and BMI, and is correlated with the radiological extent. The CRP and ESR were found to be useful in differential diagnosis of tuberculosis and pneumonia.

Key words: pulmonary tuberculosis, pneumonia, serum lipids, proteins, radiology.

\section{Introduction}

Several studies have been published indicating that cholesterol might have an important role in cellular immunity, and low cholesterol might have destructive effects on lymphocytes and macrophages facilitating the development and progression of tuberculosis [1, 2]. Serum levels of total cholesterol have been found to be low in patients with pulmonary tuberculosis and a cholesterol rich diet might accelerate sterilization of the sputum in these patients [3]. HDL cholesterol has also been shown to be low in patients with inflammatory diseases such as pneumonia and tuberculosis $[4,5]$ and a relationship has been emphasized between acute phase reactants and $\mathrm{HDL}$ cholesterol $[4,6]$. In addition, a relationship has been

\author{
Corresponding author: \\ Füsun Șahin MD \\ Department of Pulmonology \\ Yedikule Chest Diseases \\ and Thoracic Surgery \\ Training and \\ Research Hospital \\ Postal code: 34760 \\ Zeytinburnu/Istanbul, Turkey \\ Phone: +90 2126641700 \\ Fax: +90 2125472233 \\ E-mail: fusunsahin19700@ \\ hotmail.com
}


demonstrated between serum lipid levels and radiological extent in community-acquired pneumonia [4]. Together all these data suggest that a relationship might also exist between serum lipid levels and radiology of tuberculosis.

Clinicians often have difficulty regarding differential diagnosis of tuberculosis and pneumonia in cases of upper lobe located lesions [7]. Therefore, a number of studies have been conducted in order to define markers that might contribute to differential diagnosis. C-reactive protein (CRP) is one of these markers. It has been demonstrated in studies that cytokines resulting from Mycobacterium tuberculosis infection increase the production of acute phase reactants in the liver and that the level of CRP, which is one of the most important acute phase proteins, is high in tuberculosis patients $[8,9]$.

The objective of this study was to investigate the relationship between radiological extent and serum lipid parameters, protein levels and body mass index in patients with pulmonary tuberculosis and pneumonia and to determine the usefulness of CRP in clinical differentiation of tuberculosis and pneumonia.

\section{Material and methods}

This is an analytic, case-control study. The study was performed in accordance with the principles of the Declaration of Helsinki and approved by the ethics committee of the hospital (Yedikule Chest Diseases and Thoracic Surgery Training and Research Hospital, Istanbul).

One hundred fifteen consecutive patients with active lung tuberculosis referred to the Chest Diseases and Thoracic Surgery Training and Research Hospital between 2008 and 2010 (group 1; 81 male, 34 female), 70 age and gender matched patients with community-acquired pneumonia (CAP, group 2; 50 male, 20 female) and 30 healthy controls (group 3; 18 male, 12 female) were included in the study. Sputum AFB (with Ziehl-Neelsen stain) and at least one culture (Löwenstein-Jensen media and BACTEC TB 460 system) were found positive in all the patients in group 1 and accepted as active lung tuberculosis. Patients with PTB were classified as stage 1 (minimal/mild), stage 2 (moderate) and stage 3 (advanced) according to the extent of the disease on the chest radiographs [10, 11]. Lesions were considered to be 'minimal' if they were of slight to moderate density without cavitation and involved a part of one or both lungs, the total extent being less than the volume of the lung on one side which was present above the second chondrosternal junction. Moderate lesions were present in one or both lungs, but the total extent did not exceed the following limits: disseminated lesions of slight to moderate density which extended throughout the total volume of one lung, or the equivalent in both lungs; dense and confluent lesions which were limited in extent to one third the volume of one lung; total diameter of cavitation, when present, was less than $4 \mathrm{~cm}$. Lesions more extensive than these were recorded as 'advanced'. CAP (group 2) was defined as the presence of a new pulmonary infiltrate on chest radiograph that was cleared by antibiotic therapy at the time of diagnosis associated with cough. The patients with pneumonia were classified according to the chest radiographs. Chest $X$-rays were divided into the following three zones: the upper zone was above the imaginary line adjacent to the tip of the second anterior ribs, the lower zone was below the imaginary line adjacent to the tip of the fourth anterior ribs, and the middle zone was between these two zones for each hemithorax (4). Each lung zone was scored by visually estimating the degree of the extent of involvement on a 0-4 point scale for lowdensity abnormalities. The score was based on the percentage of lung parenchyma that showed involvement: 0 was normal; 1 , involvement of less than $25 \%$ of a zone; $2,25-50 \%$; $3,50-75 \%$; 4 , more than $75 \%$ involvement [4]. Subjects were excluded if there was a history of severe cardiovascular disease, significant liver or autoimmune disorders, neoplasm and immunosuppressive conditions. Normal healthy individuals who presented for routine examination, who did not have any complaint or known disease, with normal chest radiograph, were included in the control group. Full blood counts were carried out using ABX Pentra 120 (Minnesota, USA); serum total cholesterol (TC), HDL, LDL, VLDL, triglyceride (TG), total protein (TP), albumin (ALB ) and CRP with Olympus AU2700 Plus, Beckman Coulter (Tokyo, Japan); and ESR (erythrocyte sedimentation rate) with Eriline AR Linear (Barcelona, Spain) devices in each of the three group. Besides intergroup comparisons, intra-group comparisons were also carried out in the groups divided according to the radiological staging (tuberculosis stages 1, 2, 3 and pneumonia stages $1,2,3,4$ ).

\section{Statistical analysis}

All the statistical analyses were carried out using SPSS 11.5 package software (SPSS Inc., Chicago, IL, USA). Inter-group comparisons were performed with one-way analysis of variance, correlations between numerical parameters with Pearson's correlation test, and correlation between one numerical and one categorical or two categorical parameters with Spearman's correlation test. Mann-Whitney $U$ test was used in intra-group comparison of laboratory values between different radiological stages in each tuberculosis and pneumonia group. Values of $p$ less than 0.05 were considered statistically significant. The best cut-off value of serum CRP in differentiation of tuberculosis and pneumonia was calculated 
with the receiver operating characteristic (ROC) curve.

\section{Results}

Age, body mass index (BMI) and laboratory values (mean \pm SD) of the patients with tuberculosis and pneumonia and healthy controls, and intragroup comparison of each group are presented in Table I.

Laboratory outcomes of lipid values (TC, TG, HDL, LDL, VLDL) in the tuberculosis and pneumonia groups and their correlations with BMI and radiological stages (RS) are shown in Tables II and III. In addition, radiological stages (stages 1, 2, and 3), BMI and laboratory outcomes were compared in the tuberculosis group itself. In the tuberculosis group, BMI, HDL, TG, TP and ALB were found to decrease, while CRP and ESR increased as the radiological stage (stages 1,2 and 3 ) increased $(p<0.05)$. How- ever, no significant difference was found in TC and LDL as the radiological extent increased $(p>0.05)$. In the pneumonia group, BMI, TC, HDL, LDL, TP and ALB were observed to decrease, while LEU (leukocyte), CRP and ESR increased as the radiological stage (stages 1, 2, 3 and 4$)$ increased $(p<0.05)$.

The best serum CRP cut-off value in differential diagnosis of tuberculosis and pneumonia was defined as 9.4. For this cut-off value, sensitivity was found as $70 \%$, specificity as $71 \%$, positive predictive value as $79.4 \%$ and negative predictive value as $59 \%$ (Table IV).

\section{Discussion}

Plasma lipid levels might be influenced in infectious and inflammatory diseases. Lower levels of TC found in tuberculosis patients compared to healthy controls is consistent with previously reported results in conditions leading to tuberculosis and

Table I. Mean (SD) levels of age, BMI and laboratory parameters for tuberculosis, pneumonia and control groups and $p$ values of their comparisons

\begin{tabular}{|lllllcc|}
\hline Parameter & $\begin{array}{l}\text { Tuberculosis } \\
\text { Mean (SD) }\end{array}$ & $\begin{array}{l}\text { Pneumonia } \\
\text { Mean (SD) }\end{array}$ & $\begin{array}{l}\text { Control } \\
\text { Mean (SD) }\end{array}$ & T-C & P-C & T-P \\
\hline Age [years] & $39.57(14.99)$ & $42.60(16.37)$ & $39.56(12.44)$ & NS & NS & NS \\
\hline BMI [kg/m²] & $19.41(1.89)$ & $20.74(1.23)$ & $22.67(0.82)$ & $<0.001$ & $<0.001$ & $<0.001$ \\
\hline Hemoglobin [g/l] & $12.28(1.73)$ & $12.65(1.60)$ & $13.42(0.98)$ & $<0.001$ & 0.013 & NS \\
\hline Leucocyte $\left[10^{3} / \mathrm{\mu l}\right]$ & $8593(2182)$ & $17640(4307)$ & $7200(1489)$ & $<0.001$ & $<0.001$ & $<0.001$ \\
\hline ESR [mm/h] & $71.83(25.76)$ & $85.81(24.55)$ & $15.70(3.64)$ & $<0.001$ & $<0.001$ & 0.001 \\
\hline CRP [mg/l] & $7.27(5.57)$ & $14.32(7.19)$ & $0.42(0.28)$ & $<0.001$ & $<0.001$ & $<0.001$ \\
\hline $\begin{array}{l}\text { Total cholesterol } \\
\text { [mmol/l] }\end{array}$ & $137.21(20.80)$ & $146.11(34.85)$ & $164.30(23.98)$ & $<0.001$ & 0.011 & NS \\
\hline HDL [mmol/l] & $33.25(7.21)$ & $32.45(11.72)$ & $48.60(5.22)$ & $<0.001$ & $<0.001$ & NS \\
\hline LDL [mmol/l] & $84.70(17.85)$ & $88.70(28.73)$ & $98.93(21.56)$ & 0.006 & NS & NS \\
\hline VLDL [mmol/l] & $18.87(7.76)$ & $25.07(15.10)$ & $17.80(5.62)$ & NS & 0.002 & 0.006 \\
\hline Triglyceride [mmol/l] & $66.51(19.71)$ & $112.55(41.42)$ & $107.43(28.28)$ & $<0.001$ & NS & $<0.001$ \\
\hline Total protein [g/l] & $6.80(0.62)$ & $6.65(0.67)$ & $7.03(0.44)$ & NS & 0.003 & NS \\
\hline Albumin [g/l] & $3.20(0.44)$ & $3.33(0.51)$ & $4.09(0.38)$ & $<0.001$ & $<0.001$ & NS \\
\hline
\end{tabular}

NS - not significant, SD - standard deviation, BMI - body mass index, ESR - erythrocyte sedimentation rate, CRP-C-reactive protein

Table II. Correlations between laboratory parameters and other parameters in tuberculosis group

\begin{tabular}{|c|c|c|c|c|c|c|c|c|c|}
\hline & $\begin{array}{c}\mathrm{TC} \\
r\end{array}$ & $\begin{array}{c}\mathrm{TG} \\
r\end{array}$ & $\begin{array}{c}\mathrm{HDL} \\
r\end{array}$ & $\begin{array}{c}\mathrm{LDL} \\
r\end{array}$ & $\begin{array}{c}\text { VLDL } \\
r\end{array}$ & $\begin{array}{c}\mathrm{TP} \\
r\end{array}$ & $\begin{array}{c}\text { ALB } \\
r\end{array}$ & $\begin{array}{c}\text { CRP } \\
r\end{array}$ & $\begin{array}{c}\text { BMI } \\
r\end{array}$ \\
\hline RS & NS & $-0.29^{*}$ & $-0.33^{\star *}$ & NS & $-0.43^{\star *}$ & $-0.29^{\star *}$ & $-0.21^{\star}$ & $0.48^{* *}$ & $-0.38^{\star *}$ \\
\hline $\mathrm{BMI}$ & $0.28^{\star *}$ & NS & $0.29^{\star *}$ & NS & $0.31^{\star *}$ & NS & $0.37^{\star \star}$ & $-0.18^{\star}$ & \\
\hline LEU & NS & NS & NS & $0.26^{\star *}$ & NS & NS & $-0.27^{\star \star}$ & $0.40^{\star *}$ & $-0.37^{\star *}$ \\
\hline $\mathrm{HB}$ & NS & NS & $0.18^{*}$ & $0.19^{\star}$ & $-0.18^{\star}$ & $0.23^{*}$ & $0.41^{\star \star}$ & $-0.38^{\star *}$ & $0.21^{*}$ \\
\hline ALB & $0.28^{\star *}$ & NS & $0.37^{\star *}$ & NS & NS & $0.50^{\star *}$ & & $-0.35^{\star *}$ & $0.37^{\star *}$ \\
\hline
\end{tabular}

${ }^{*} p<0.05,{ }^{* *} p<0.001, r$ - correlation value, $R S$ - radiological stage, HB - hemoglobin, TP - total protein, ALB - albumin, TC - total cholesterol, $T G$ - triglyceride, LEU - leucocyte. Other abbreviations - see Table I 
Table III. Correlations between laboratory parameters and other parameters in pneumonia group

\begin{tabular}{|c|c|c|c|c|c|c|c|c|c|}
\hline & $\begin{array}{c}\mathrm{TC} \\
r\end{array}$ & $\begin{array}{c}\text { TG } \\
r\end{array}$ & $\begin{array}{c}\mathrm{HDL} \\
r\end{array}$ & $\begin{array}{c}\mathrm{LDL} \\
r\end{array}$ & $\begin{array}{c}\text { VLDL } \\
r\end{array}$ & $\begin{array}{c}\text { CRP } \\
r\end{array}$ & $\begin{array}{c}\mathrm{TP} \\
r\end{array}$ & $\begin{array}{c}\mathrm{ALB} \\
r\end{array}$ & $\begin{array}{c}\text { BMI } \\
r\end{array}$ \\
\hline RS & $-0.43^{\star *}$ & NS & $-0.26^{\star}$ & $-0.35^{\star \star}$ & NS & 0.35 & $-0.27^{\star}$ & $-0.30^{*}$ & $-0.27^{\star}$ \\
\hline BMI & $0.36^{\star \star}$ & NS & $0.31^{\star \star}$ & $0.28^{\star}$ & NS & NS & NS & NS & \\
\hline $\mathrm{HB}$ & NS & NS & $0.41^{\star \star}$ & NS & $0.37^{\star \star}$ & NS & NS & NS & $0.33^{* *}$ \\
\hline TP & $0.28^{*}$ & NS & $0.35^{\star \star}$ & NS & NS & NS & & $0.63^{\star \star}$ & NS \\
\hline ALB & $0.25^{*}$ & NS & $0.52^{\star \star}$ & NS & NS & NS & $0.63^{* *}$ & & NS \\
\hline LEU & NS & NS & NS & NS & NS & $0.29^{*}$ & NS & NS & $-0.32^{\star \star}$ \\
\hline
\end{tabular}

Abbreviations - see Tables I and II

Table IV. Sensitivity, specificity, positive predictive value and negative predictive value of the different CRP cut-off levels in differential diagnosis between tuberculosis and pneumonia

\begin{tabular}{|ccccc|}
\hline $\begin{array}{c}\text { Serum CRP levels } \\
{[\mathrm{mg} / \mathrm{l}]}\end{array}$ & $\begin{array}{c}\text { Sensitivity } \\
{[\%]}\end{array}$ & $\begin{array}{c}\text { Specificity } \\
{[\%]}\end{array}$ & $\begin{array}{c}\text { Positive predictive value } \\
{[\%]}\end{array}$ & $\begin{array}{c}\text { Negative predictive value } \\
{[\%]}\end{array}$ \\
\hline 8 & 78.6 & 59 & 81.9 & 53.9 \\
\hline 9.4 & 70 & 71 & 79.4 & 59 \\
\hline 11.7 & 60 & 81 & 76.9 & 65.6 \\
\hline
\end{tabular}

other infectious/inflammatory situations (e.g. pneumonia) [3, 5, 12]. The correlation between low serum levels of TC and progression of tuberculosis indicated an inverse relation between inflammation and serum value of TC. Accordingly, numerous studies report significant reduction in serum level of HDL. In a study from Mexico conducted to evaluate the hypothesis that low serum levels of cholesterol might be a risk factor in development of pulmonary tuberculosis, levels of TC, HDL, LDL and TG were

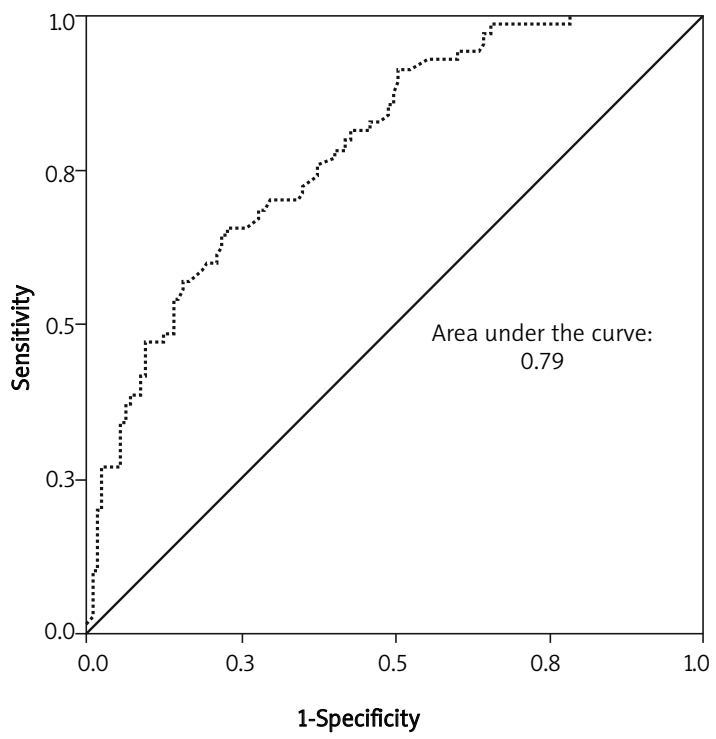

Figure 1. ROC curve for using serum CRP levels in differential diagnosis of pulmonary tuberculosis and pneumonia found to be lower in tuberculosis patients than in persons with household contact [13]. In a study, low levels of TC were reported in surgical patients in a critical condition [14], while in another study, acute phase markers were reported to be negatively correlated with serum values of TC in hospitalized elderly patients [6]. Furthermore, similar to other studies, in these studies also levels of HDL and LDL were found to decrease due to inflammation in tuberculosis patients $[3,6,14,15]$. Deniz et al. found sig-

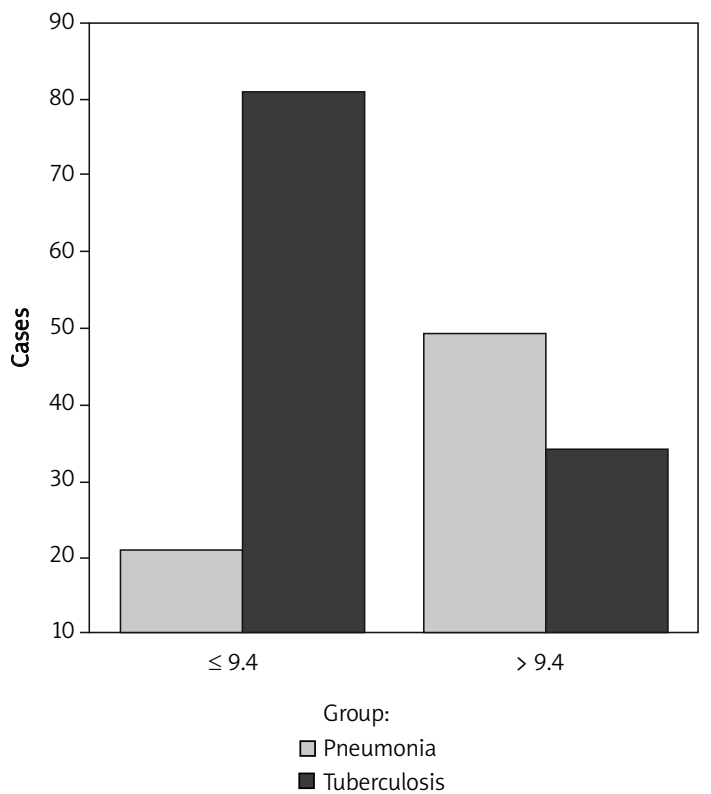

Figure 2. Comparison of groups at the best cut-off point $(9.4 \mathrm{mg} / \mathrm{l})$ 
nificantly lower serum levels of HDL in patients with community-acquired pneumonia than in healthy controls and an inverse relation between the radiological extent and HDL [4]. In addition, these authors found serum lipid levels, especially levels of $\mathrm{HDL}$, to be low in pulmonary tuberculosis compared to the healthy group [3]. They underline that low levels of HDL in tuberculosis might be related to acute phase proteins (particularly secretory phospholipase A2 and serum amyloid A) induced by mediators during the inflammatory process [3]. Similarly, serum levels of LDL were found to be low during the infection and inflammation process, and this was thought to be associated with possibly increased LDL oxidation [3, 16]. Gruber et al. stated that low lipid levels, especially low HDL, point to a bacterial infection [17]. Rodriguez Reguero et al. underlined that low levels of HDL are found especially in non-viral atypical pneumonias [5]. In their study with patients in the intensive care unit, Lüthold et al. found levels of HDL and total cholesterol lower in the infection group and stated that the diagnostic benefit of HDL is superior to CRP [18]. In our study, levels of TC, HDL, LDL and TG were found significantly lower in the tuberculosis group than in the healthy controls. On radiological examination, serum levels of HDL and TG were shown to be lower in patients in an advanced stage of tuberculosis (particularly patients having cavitary lesions) than in patients with minimal or moderate stages due to the increased inflammation. However, unlike other studies, no significant difference was found in levels of TC and LDL as the radiological extent increased in the tuberculosis group. Consistently with the literature, levels of HDL, LDL and TC were found to be lower in patients with pneumonia and inversely proportional to the radiological stage. Interestingly, no significant difference was found in TG as the radiological extent increased in the pneumonia group. Even more interesting, TG levels in the pneumonia group were similar in the healthy control group (pneumonia: $112.55 \pm 41.42$; healthy control: $107.43 \pm 28.28$ ). Triglycerides levels were much lower in the tuberculosis group than in the pneumonia group. In addition to other studies, our study showed that TG levels were important in the evaluation of tuberculosis severity and the differentiation from pneumonia.

Weight loss seen in tuberculosis is believed to be primarily caused by the acute phase response of the host. Release of proinflammatory cytokines induced by the viral or bacterial products takes part among the other causes. Both infection agent-related products and cytokines with increased release due to these products cause a decrease in appetite, resulting in weight loss [19]. C-reactive protein is an acute phase protein that is a non-specific marker of systemic inflammation. Acute phase reactants such as CRP increase and weight loss-related BMI decreases as the radiological extent increases [20]. The value of CRP as a marker was studied in a population with lower respiratory bacterial infection, and it was found to be useful to evaluate severity of the disease [21]. For example, levels of CRP were found to be higher in patients with HIV-positive community-acquired pneumonia than in those with tuberculosis [22]. In a study conducted in Finland, no significant difference was found between levels of CRP in differentiation between pulmonary tuberculosis and malignant intrathoracic tumors; however, quite significant levels of CRP were found in the tuberculosis patients presenting cavitation on chest radiographs than in the healthy controls [23]. In a study conducted in our country, serum levels of CRP were found quite higher in the tuberculosis patients than in the controls, with a prominent elevation in levels of CRP with weight loss, especially in persons who had cavitation and advanced lesions. This was emphasized to be a good marker in definition of the disease severity [8]. In a study from China, levels of CRP were measured in various pulmonary infections (e.g. tuberculosis, pneumonia and abscess) and different levels were observed in each type of infection. Levels of CRP were reported to be a good marker in defining the severity of inflammation and monitoring the response to treatment [24]. In a study from Brazil with 28 tuberculosis patients, cytokines and acute phase reactants were measured at the beginning and at the $3^{\text {rd }}$ and $6^{\text {th }}$ months. C-reactive protein and ESR were reported as potential tuberculosis markers in patients with (-) sputum AFB. Especially CRP was emphasized to be a good marker indicating a response to the treatment [25]. In a study conducted in Korea, CRP was examined in 87 patients with suspected community-acquired pneumonia and 57 of them were definitely diagnosed with community-acquired pneumonia and 30 with tuberculosis. Measuring the serum levels of CRP was stated to have a high sensitivity and negative predictive value [26]. In a similar study, levels of CRP were studied in 46 tuberculosis and 67 pneumonia patients and were found to be lower in the tuberculosis patients. Furthermore, sensitivity of the levels under 11.2 was found as $93.3 \%$ and specificity as $40.9 \%$ in differentiation of tuberculosis and pneumonia [27]. In this study, we found the best cut-off value as 9.4 (specificity $71 \%$, sensitivity $70 \%$ ) in differentiation of tuberculosis and pneumonia.

Serum levels of ESR and ALB are also good markers of the acute phase response, likewise CRP. Erythrocyte sedimentation rate was found to be high in patients with elevated serum levels of CRP, but levels of ALB were lower [8, 28]. In addition, anemia was also identified in tuberculosis patients, and a significant negative correlation was observed 
between $\mathrm{Hb}$ (hemoglobin) and CRP $[8,28]$. Similar to the above-mentioned studies, in our study, we found ESR and CRP to increase, while HDL, ALB, HB and $\mathrm{BMI}$ decreased as the radiological extent increased, especially in tuberculosis.

In conclusion, our study demonstrated that the acute phase response occurring in diseases causing inflammation such as tuberculosis and pneumonia determines the severity of the disease, leads to decrease of the serum levels of lipoprotein and $\mathrm{BMI}$ and is positively correlated with the radiological extent. In addition, our findings suggested CRP and ESR, which are acute phase reactants, to be useful in differential diagnosis and as potential tuberculosis markers in patients with $(-)$ sputum AFB. Furthermore, our study showed that TG levels were important in the evaluation of tuberculosis severity and differentiation from pneumonia.

\section{References}

1. Gatfield PJ. Essential role for cholesterol in entry of mycobacteria into macrophages. Science 2000; 288: 1647-50.

2. Deniz O, Gumus S, Yaman H, et al. Serum total cholesterol, HDL-C and LDL-C concentrations significantly correlate with the radiological extent of disease and the degree of smear positivity in patients with pulmonary tuberculosis. Clin Biochem 2007; 40: 162-6.

3. Perez-Guzman C, Vargas MH, Quinonez F, Bazavilvazo N, Aguilar A. A cholesterol-rich diet accelerates bacteriologic sterilization in pulmonary tuberculosis. Chest 2005; 127: 643-51.

4. Deniz O, Tozkoparan E, Yaman H, et al. Serum HDL-C levels, log (TG/HDL-C) values and serum total cholesterol/HDL-C ratios significantly correlate with radiological extent of disease in patients with community-acquired pneumonia. Clin Biochem 2006; 39: 287-92.

5. Rodriguez Reguero JJ, Iglesias Cubero G, Vazgues M, et al. Variation in plasma lipid and lipoprotein concentrations in community-acquired pneumonia a six-month prospective study. Eur J Clin Chem Clin Biochem 1996; 34: 245-9.

6. Volpato S, Palmieri E, Fellin R, Zuliani G. Acute phase markers are associated with reduced plasma lipid concentrations in a population of hospitalized elderly patients. Gerontology 2000; 46: 22-7.

7. Siddiqi K, Lambert ML, Walley J. Clinical diagnosis of smear negative pulmonary tuberculosis in low-income countries: the current evidence. Lancet Infect Dis 2003; 3: 288-96.

8. Caner SS, Köksal D, Özkara Ș, Berkoğlu M, Aksaray S, Tarhan D. The relation of serum interleukin-2 and C-reactive protein levels with clinical and radiological findings in patients with pulmonary tuberculosis. Tuberk Toraks 2007; 55: 238-45.

9. Immanuel C, Acharyulu GS, Kannapiran M, Segaran R, Sarma GR. Acute phase proteins in tuberculous patients. Indian J Chest Dis Allied Sci 1990; 32: 15-23.

10. National Tuberculosis Association of the USA. Diagnostic standards and classification of tuberculosis. National Tuberculosis Association, New York, 1961.

11. Seaton A, Seaton D, Leitch AG. Crofton and Douglas's respiratory diseases. In: Clinical features of tuberculosis. $4^{\text {th }}$ ed. Blackwell, Oxford 1989; 409-10.
12. Kerttula $Y$, Weber T. Serum lipids in pneumonia of different aetiology. Ann Clin Res 1988; 20: 184-8.

13. Pérez-Guzmán C, Vargas MH, Salas-Mártir C, TrejoSantacruz T, Gallegos-Discua C, Flores-López F. Lipid profile in household contacts of patients with pulmonary tuberculosis. Rev Med Inst Mex Seguro Soc 2008; 46: 247-52.

14. Gordon B, Parker T, Levine D, et al. Relationship of hypolipidemia to cytokine concentrations and outcomes in critically ill surgical patients. Crit Care Med 2001; 29: 1563-8.

15. Tietge UJ, Maugeais C, Lund-Katz S, Grass D, de Beer FC, Rader DJ. Human secretory phospholipase A2 mediates decreased plasma concentrations of HDL-C cholesterol Apoa-I transgenic mice. Arterioscler Thromb Vasc Biol 2002; 22: 1213-8.

16. Cabana VG, Siegel JN, Sabesin SM. Effects of the acute phase response on the concentration and density distribution of plasma lipids and apolipoproteins. J Lipid Res 1989; 30: 39-49.

17. Gruber M, Christ-Crain M, Stolz D, et al. Prognostic impact of plasma lipids in patients with lower respiratory tract infections - an observational study. Swiss Med Wkly 2009; 139: 166-72.

18. Lüthold S, Berneis K, Bady P, Müller B. Effects of infectious disease on plasma lipids and their diagnostic significance in critical illness. Eur J Clin Invest 2007; 37: 573-9.

19. Davies PDO. Clinical tuberculosis. Chapman \& Hall Medical, USA 1994.

20. Caplin M, Grange JM, Morley S, et al. Relationship between radiological classification and the serological and haematological features of untreated pulmonary tuberculosis in Indonesia. Tubercle 1989; 70: 103-13.

21. Almirall J, Bolibar I, Toran P, et al. Contribution of C-reactive protein to the diagnosis and assessment of severity of community-acquired pneumonia. Chest 2004; 125: 1335-42.

22. Schleicher $G K$, Herbert V, Brink A, et al. Procalcitonin and C-reactive protein levels in HIV-positive subjects with tuberculosis and pneumonia. Eur Respir J 2005; 25: 688-92.

23. Peresi E, Silva SM, Calvi SA, Marcondes-Machado J. Cytokines and acute phase serum proteins as markers of inflammatory regression during the treatment of pulmonary tuberculosis. J Bras Pneumol 2008; 34: 942-9.

24. Lin MS, Chong IW, Hwang JJ, et al. Quantitative C-reactive protein in pulmonary infections. Gaoxiong Yi Xue Ke Xue Za Zhi 1990; 6: 440-8.

25. Peresi E, Silva SM, Calvi SA, Marcondes-Machado J. Cytokines and acute phase serum proteins as markers of inflammatory regression during the treatment of pulmonary tuberculosis. J Bras Pneumol 2008; 34: 942-9.

26. Kang YA, Kwon SY, Yoon HI, Lee JH, Lee CT. Role of Creactive protein and procalcitonin in differentiation of tuberculosis from bacterial community acquired pneumonia. Korean J Intern Med 2009; 24: 337-42.

27. Choi CM, Kang Cl, Jeung WK, Kim DH, Lee CH, Yim JJ. Role of the C-reactive protein for the diagnosis of TB among military personnel in South Korea. Int J Tuberc Lung Dis 2007; 11: 233-36.

28. Turken O, Kunter E, Sezer M, et al. Hemostatic changes in active pulmonary tuberculosis. Int I Tuberc Lung Dis 2002; 6: 927-32. 